Digital Circuits for Binary Arithmetic 


\section{Digital Circuits for Binary Arithmetic}

R. M. M. Oberman

Professor in Information Engineering

Technical University

Delft, The Netherlands 
(C) R. M. M. Oberman 1979

Softcover reprint of the hardcover 1st edition 1979 978-0-333-25535-3

All rights reserved. No part of this publication may be reproduced or transmitted, in any form or by any means, without permission

First published 1979 by

THE MACMILLAN PRESS LTD

London and Basingstoke

Associated companies in Delhi Dublin

Hong Kong Johannesburg Lagos Melbourne

New York Singapore and Tokyo

Typeset by

Reproduction Drawings Ltd., Sutton, Surrey

\section{British Library Cataloguing in Publication Data}

Oberman, Roelof Maarten Marie

Digital circuits for binary arithmetic.

1. Digital electronics

I. Title

$621.3815^{\prime} 3$

TK7868.D5

ISBN 978-1-349-04244-9 ISBN 978-1-349-04242-5 (eBook)

DOI 10.1007/978-1-349-04242-5

No technical science

can exist without

addition of numbers

This book is sold subject to the standard condition of the Net Book Agreement 


\section{Contents}

Preface $\quad$ xi

1. Codes 1

1.0 Introduction 1

1.1 Binary Number Representation 4

1.2 The Negabinary System 7

1.3 Signed Digit Number Representation 8

1.4 Decimal Codes 9

1.5 The Complementing of Code Words 11

One's and two's complement converters 11

Programmable one's and two's complement converters $\quad 12$

1.6 Add 1 and Subtract 1 Operations 13

1.7 Complementing in the Negabinary Number System 16

1.8 Two's Complementing in the Signed-digit Number System 17

1.9 The Nine's and Ten's Complement in the BCD Code 19

1.10 Code Conversion between Number Systems with Different
Radix

1.11 Error-detecting and Error-correcting Codes 22

Parity checks 23

Constant-ratio codes $\quad 24$

$A N+B$ codes 25

Error detection in the addition of checked binary words $\quad 27$

Error correction in the addition of checked binary words $\quad 28$

Check indicator 31

Check reconstruction $\quad 36$

1.12 The Number System of Residual Classes 41

Mathematical operations in the system of residual classes $\quad 42$

Residual class to decimal code conversion 43 
2. Addition and Subtraction 46

2.0 Introduction $\quad 46$

Word-oriented addition $\quad 52$

Bit-oriented addition $\quad 53$

Overflow in the addition of binary numbers $\quad 53$

Overflow in the subtraction of binary numbers $\quad 55$

2.1 The Carry Problem $\quad 55$

2.2 Mathematical Operations in the Reflected Binary Code 67

The subtraction in the modified reflected binary code $\quad 73$

2.3 Signed Digit Addition $\quad 74$

$\begin{array}{ll}\text { Correction rules } & 83\end{array}$

2.4 Negabinary Adder $\quad 84$

2.5 Arithmetic Logic Unit 90

2.6 Error Detection in Binary Addition 98

2.7 Error Correction in Binary Addition 100

2.8 Error-Correcting Adders with Majority Decision 102

$\begin{array}{ll}\text { References } & 104\end{array}$

3. The Addition of a Number of Words 105

$\begin{array}{ll}3.0 \text { Introduction } & 105\end{array}$

$\begin{array}{lll}3.1 & \text { Bit-oriented Adders } & 108\end{array}$

3.2 Bit-addition Using ROM Circuits 113

$\begin{array}{ll}3.3 \text { Word-oriented Adders } & 118\end{array}$

$\begin{array}{lr}\text { References } & 123\end{array}$

4. Multiplication 124

$\begin{array}{ll}4.0 \text { Introduction } & 124\end{array}$

$4.14 \times 4$ Bit Parallel Multipliers $\quad 125$

Word-oriented $4 \times 4$ bit parallel multiplier $\quad 127$

Bit-oriented $4 \times 4$ bit parallel multiplier $\quad 132$

Read-only memory as parallel multiplier 133

$4 \times 4$ Bit parallel multiplier $\quad 135$

$\begin{array}{ll}4.28 \times 8 \text { Bit Parallel Multipliers } & 135\end{array}$

$\begin{array}{ll}4.316 \times 16 \text { Bit Parallel Multipliers } & 138\end{array}$

$16 \times 16$ Bit parallel multipliers, using $4 \times 4$ bit parallel

multipliers as basic elements, bit-oriented addition of

partial products

$16 \times 16$ Bit parallel multipliers, using $4 \times 4$ bit parallel multipliers as basic elements, word-oriented addition of partial products

4.4 Multiplication of Signed Numbers 146

Via a correction circuit $\quad 146$

Via two's complement transformations $\quad 148$

Booth's algorism 
Signed $2 \times 4$ bit parallel multiplier SN74LS261 151

Signed $2 \times 4$ bit parallel multiplier Am $2505 \quad 162$

$\begin{array}{lll}\text { 4.5 Parallel Multipliers with Unit Cells } & 167\end{array}$

$\begin{array}{lll}\text { 4.6 Serial-Parallel Multipliers } & 169\end{array}$

Word-oriented serial-parallel multipliers $\quad 169$

Serial-parallel multiplication of signed numbers, Booth's algorism

Bit-oriented serial-parallel multiplier $\quad 176$

4.7 Serial Multipliers

177

$\begin{array}{lr}\text { 4.8 Atrubin's Algorism } & 179\end{array}$

$\begin{array}{lr}\text { References } & 182\end{array}$

5. Division 183

$\begin{array}{ll}5.0 \text { Introduction } & 183\end{array}$

$\begin{array}{lll}5.1 & \text { The Restoring Division } & 183\end{array}$

$\begin{array}{ll}\text { 5.2 The Continuous Division } & 184\end{array}$

$\begin{array}{ll}\text { 5.3 The Continuous Non-Restoring Division } & 187\end{array}$

$\begin{array}{ll}5.4 \text { Signed Serial-Parallel Division } & 190\end{array}$

The division of signed binary numbers as reversed Booth's

algorism

194

Non-restoring serial-parallel division of signed binary numbers

197

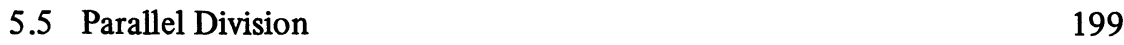

$\begin{array}{ll}\text { Signed parallel division } & 201\end{array}$

Parallel division by ROM circuits $\quad 207$

$\begin{array}{ll}5.6 \text { Serial Division } & 209\end{array}$

$\begin{array}{ll}\text { References } & 211\end{array}$

6. Binary Decimal Arithmetic $\quad 212$

$\begin{array}{ll}6.0 \text { Introduction } & 212\end{array}$

6.1 BIN $\rightarrow$ BCD Code Conversion $\quad 219$

Add-3 algorism, serial conversion $\quad 219$

Add-3 algorism, parallel conversion $\quad 222$

6.2 BCD $\rightarrow$ BIN Code Conversion $\quad 230$

Add-5 algorism, serial conversion $\quad 230$

BCD $\rightarrow$ BIN code conversion, serial-parallel $\quad 231$

Parallel BCD $\rightarrow$ BIN code conversion $\quad 232$

6.3 BIN $\leftrightarrow$ BCD Code Conversion of Fractions $\quad 237$

$\begin{array}{ll}6.4 \text { BCD Adders/Subtracters } & 241\end{array}$

The BCD adder $\quad 244$

The BCD subtracter $\quad 245$

6.5 The Design of a Single-Chip BCD Adder 249

The $\Sigma_{2}$ output circuit $\quad 253$

$\begin{array}{lll}6.6 \text { X-3 Adders/Subtracters } & 256\end{array}$ 
6.7 BCD Multiplication and Division $\quad 260$

Serial-parallel multiplication $\quad 260$

Serial-parallel division $\quad 263$

BCD Parallel multiplier $\quad 267$

References

7. Floating Point Arithmetic Circuits $\quad 270$

$\begin{array}{lll}7.0 \text { Introduction } & 270\end{array}$

Addition $\quad 271$

$\begin{array}{ll}\text { Subtraction } & 272\end{array}$

Multiplication $\quad 272$

Division $\quad 273$

7.1 Inaccuracy of Floating Point Operations 274

The associative law of addition $(a+b)+c=a+(b+c) \quad 275$

The associative law of multiplication $(a \cdot b) \cdot c=a \cdot(b \cdot c) \quad 276$

7.2 Floating Point Notation of a Binary Number 277

7.3 The Realisation of the Number Transposition 281

$\begin{array}{lll}7.4 & \text { The Exponent } & 287\end{array}$

7.5 The Rounding and Final Normalising 289

$\begin{array}{ll}\text { References } & 290\end{array}$

8. Accumulative Adding 291

$\begin{array}{ll}8.0 \text { Introduction } & 291\end{array}$

8.1 Accumulative Counters (Single Operating Mode) 292

Binary up-counter $\quad 292$

Binary down-counter $\quad 292$

N-step counter $\quad 292$

2-4-2-1 Decade counter 293

5-4-2-1 Decade counter $\quad 294$

The binary rate multiplier $\quad 295$

Arbitrary rate multiplier $\quad 297$

8.2 Accumulators with Programmable Operating Mode 299

Counter operating in the 'Colenbrander' code 299

Counters operating in a constant-ratio code 301

8.3 Single-Level Accumulators 303

The squaring of binary numbers by accumulative operation 303

$\begin{array}{ll}\text { The square root extracter } & 308\end{array}$

Error-correction in $A N$ codes $\quad 314$

$\begin{array}{ll}8.4 \text { Multi-Level Accumulators } & 319\end{array}$

$N_{\alpha}^{2}$ Generating circuit $\quad 319$

$N_{\alpha}^{3}$ Generating circuit $\quad 321$

Sin-cos generator $\quad 322$

8.5 Miscellaneous Types of Circuits 324

Counting square root extracter $\quad 324$ 
$\begin{array}{lll}\text { 8.6 Multiplicative Accumulator } & 327\end{array}$

MacLaurin series expansion $\quad 328$

Newton-Raphson algorism $\quad 329$

Implementation of equation $X \cdot Y+Z$

8.7 Realisation of an Accumulator 333

$\begin{array}{ll}\text { References } & 338\end{array}$

$\begin{array}{ll}\text { Index } & 339\end{array}$ 


\section{Preface}

Since the publication of the first book on electronic switching circuits by the staff of the Computation Laboratory of Harvard University in 1951 (Synthesis of Electronic Computing and Control Circuits, Harvard University Press, Massachusetts) many books on digital switching circuits and systems have been published, most of them starting with the fundamentals of switching algebra based on Boolean algebra (C. E. Shannon, Symbolic Analysis of Relay and Switching Circuits).

The field of application of digital techniques and systems has, since then, enormously increased in size and importance. The medium- and large-scale integrated circuits have introduced such a high degree of complexity and sophistication that many users of these switching elements only know how to apply them in accordance with the instructions given in the manufacturer's catalogue, but do not fully understand how they actually operate. Many users will never question the switching methods used in these sophisticated integrated circuits, nor will they criticise their application as long as a working system is obtained.

It requires a team of digital switching specialists and a handbook consisting of several volumes to discuss all the commercially available digital integrated circuits manufactured in various integration techniques. However, when limiting this field to TTL integrated circuits implementing one or other algorism based on addition, and with that also subtraction, multiplication and division, it is possible to compile a moderately sized text on the design of 'Digital Circuits for Binary Arithmetic'. This means there is a limitation and, there are several reasons why this text cannot be complete. Firstly, so many ingeneous switching proposals in which addition plays a part have been published in recent years that only the most important fundamental ideas could be incorporated in this introduction. Secondly, other bright ideas in this field will be published between the writing of this text and its publication.

The text of this book is not limited to the already published ideas about digital switching methods using addition algorisms and their commercially available implementations. It shows in many cases what is still missing or what alternative switching methods could also be considered. For a number of switching circuits the 
economics of certain methods are considered and alternative, more economic, switching methods with existing integrated circuits are given. Cost improvements varying from $3: 1$ to about $10: 1$ can be obtained.

After discussing the fundamentals of the codes, the addition and subtraction of numbers in these codes are treated and considered from many points of view. This is a preparation for the discussion of the more complicated ideas behind the implementation of the multiplication and the division, as realised in a number of integrated circuits.

Applications of the fundamental methods are discussed in the chapters on BCD arithmetic, floating point arithmetic, accumulators and miscellaneous adding algorisms.

This book is not a summary of catalogue ideas and items; it shows a systematic and thoroughly argumented development of digital switching ideas. It can be used as a textbook for teachers and graduate-level students. It might cause them to doubt the quality of the information sometimes printed elsewhere. Moreover, many scientific workers in laboratories and industry will find useful information in this introduction to additive digital switching that cannot be found in the manufacturers' catalogues.

The author thanks T. van Onzen for checking and testing many of the circuit ideas given in this text, H. A. Vink for the thoroughness of reading the text itself and to the members of his staff who have contributed their ideas. The author is responsible for drawing the diagrams and has paid much attention to it, as in many cases the form of these diagrams is instrumental to the explanation of their operation. 